\title{
Socio-demographic determinants and access to prenatal care in Italy
}

Manuela Chiavarini ${ }^{1}$, Donatella Lanari ${ }^{2}$, Liliana Minelli ${ }^{1}$ and Luca Salmasi ${ }^{1 *}$

\begin{abstract}
Background: Many governments have made commitments to examine inequalities in healthcare access based on studies assessing the association between several socio-demographic factors and late initiation or fewer prenatal examinations. This study addressed the question of whether socio-demographic determinants were significant in explaining differences in prenatal care in one administrative region of Italy, Umbria.

Methods: Data were obtained from the administrative source of the regional Standard Certificate of Live Births between 2005 and 2010, and were merged with Census data to include a socio-economic deprivation index. Standard and multilevel logistic regression models were used to analyze the magnitude of various individual-level maternal characteristics and socio-demographic indicators, such as nationality, employment status, education with respect to late access to the first examination, and low number of medical visits.

Results: The study involved approximately 37,000 women. The heterogeneous effects of socio-demographic variables were documented on the prenatal care indicators analyzed. A multivariate model showed that women born outside Italy had a higher probability of making their first visit later than the 12th week of pregnancy and low numbers of prenatal medical visits; the estimated odds ratio for the analyzed indicators range from 2.25 to 3.05 . Inadequate prenatal healthcare use was also observed in younger and pluriparous women and those with low education; in addition, having a job improved the use of services, possibly through transmission of information of negative consequences due to delayed or few prenatal visits. Interestingly, this study found a substantial reduction in the number of pregnant women who do not use prenatal healthcare services properly.
\end{abstract}

Conclusions: The aim of this research is to provide more accurate knowledge about the inadequate use of prenatal healthcare in Italy. Results highlight the existence of differences in healthcare use during pregnancy, especially for women from less advantaged social classes (i.e., unemployed or poorly educated). Such inequalities should be examined in all areas of public policy and public services, to ensure equal opportunity for their use.

\section{Background}

Prenatal healthcare (PNC) has the potential to reduce perinatal morbidity and mortality by identifying and reducing potential risks, treating medical conditions, and promoting healthier lifestyles. Prenatal care includes identification of medical conditions which require careful surveillance throughout pregnancy and which may be due to individual and/or contextual characteristics. The use of PNC has largely contributed to the decrease in perinatal and infant mortality rates in high-income countries over the last century, but access to PNC is still not equally practised by some

\footnotetext{
* Correspondence: luca.salmasi@progetti.unipg.it

'Department of Experimental Medicine, Public Health Section, University of Perugia, Perugia, Italy

Full list of author information is available at the end of the article
}

groups of the population, even if prenatal care is universally and easily available. Promoting adequate access to PNC, especially among the most vulnerable groups of the population, may help to reduce differences in birth weight, infant mortality and morbidity rates, and serve as a guide for further improvements in the quality of care ${ }^{\mathrm{a}}$. We follow [1] in defining adequate access to PNC as the fulfillment of at least four antenatal visits or the observance of the first visit before the 12th gestational week. Moreover, we will use the term "access" as "realized access" or "use" of PNC services.

The Italian Health Service (IHS) is based on the principle of universal coverage. The IHS is financed by general taxation, and has decentralized governance, ensuring that national guidelines and established targets are implemented throughout the country by way of the local administrations

\section{Biomed Central}


of nineteen regions and two autonomous provinces, which are responsible for managing assigned budgets, healthcare organization and local performance. Decentralized governance is then responsible for ensuring the delivery of PNC services by means of public and private accredited hospitals. The IHS provides universal coverage and free prenatal healthcare at point of delivery to all Italian and European Union nationals. Regardless of coverage, emergency treatment is available free of charge or at low-cost to anyone who requires it in Italy. In particular, the IHS offers 4 visits during pregnancy without any charge, and the program of these visits is the same for all women. During the first visit, which ideally is done before the 12th gestational week, women receive information about services offered and courses promoted by the IHS, and about screening tests. The other visits include discussion of screening tests or other results. Receiving fewer than 4 visits or making the first visit after the 12th gestational week will be considered hereafter as inadequate.

As in the study by [2], here we investigate the relationship between various determinants and the utilization of healthcare services. The framework of [3] on health behavior adopted in this work is useful because it incorporates the distinction between various individual determinants, e.g. the predisposition of the patient, the ability to secure service use, and possibly disease level. In particular, demographic, social and attitudinal variables are complemented if a person has a regular source of care, which reflects the potential accessibility of healthcare.

Previous studies have shown that young maternal age [4-6], low education [2,6-9], unemployed status [10,11], immigrant status $[8,12,13]$, pluriparous status $[5,8,14]$ and single marital status [6,15-17] are all barriers to early initiation of prenatal care and to an appropriate number of prenatal examinations.

To describe the influence of which determinants are related to late and/or inadequate $\mathrm{PNC}$, together with individual-level maternal characteristics, this paper examines the role of predisposing, enabling, and pregnancyrelated factors on adequate prenatal care use by including in the analysis differences in socio-economic conditions related to the mother's place of residence in Umbria ${ }^{\mathrm{b}}$ [3].

Our contribution to the existing literature also lies in the estimation of the evolution over time of PNC use by exploiting the relatively long time-span covered by our data (2005-2010), from which we can provide insights on the advertising campaigns promoted by the Umbria region in 2005 regarding the benefits for mothers and newborn infants of following prenatal guidelines.

\section{Methods}

\section{Data sources}

Our study is based on data from the Standard Certificate of Live Birth (SCLB) forms of the Umbria region (Italy) between 2005 and 2010. This data source provides information on births for the entire population of the region. In Italy, state law requires certificates to be compiled for all births. To ensure uniform methodology applied to regional surveys and to obtain datasets containing comparable indicators, all regions are required to compile the same form, the "Standard Certificate of Live Birth" (SCLB). The midwife or obstetrician who attends the birth, or the doctor responsible for delivery in the operating theatre (in hospital), must complete the SCLB within 10 days of delivery, reporting epidemiological information regarding the mother's state of health, sociodemographic characteristics, risk factors during the pregnancy, obstetric procedures, characteristics and method of delivery (e.g., normal delivery or caesarian section), and inclusion of any abnormal conditions or congenital anomalies of the infant, cause of mortality, information about use of prenatal care services, etc. (for further details, see Decree No. 349 of the Italian Ministry of Health, [18]). We used population data from the Umbria region, which merges data from each mother and her baby for a total of 37,000 records.

\section{Variables of interest and descriptive analyses}

We followed the healthcare indicators recommended by [1] for monitoring and evaluating maternal and child health in the perinatal period and considered two binary indicators of access to prenatal care from the $\operatorname{SCLB}^{\mathrm{c}}[6]$ :

1. Number of prenatal visits: low number of prenatal medical visits ${ }^{\mathrm{d}}$ [14] (LPV) (below 4) and standard number of prenatal visits (SPV) (at least 4).

2. Timing of first visit: late first visit ${ }^{\mathrm{e}}$ [19] (LFV) (after more than 12 weeks) and regular timing of first visit (RFV) (fewer than 12 weeks) ${ }^{\mathrm{f}}$ [2].

As determinants, we considered a set of individuallevel variables as follows: age, with four categories: $\leq 20$, 20-29, 30-39, > 39 (reference category: age 20-29); nationality of mother, with three categories: Italian (ITA), European Union (EU-27), and rest of the world (Extra EU-27) (reference category: Italy); marital status, with two categories: married, unmarried (reference category: married). Education was measured as self-reported level of education, according to the International Standard Classification of Education (ISCED): low (not more than 8 years of education), medium (from 9 to 13 years), and high (more than 13 years); the latter was used as the reference category. Employment status was classified into five categories: self-employed or white-collar workers, blue-collar workers, unemployed, looking for a first job, and students or housewives (reference category: selfemployed or white collar). We also examined the impact of pregnancy factors on preterm birth by including 
women with previous pregnancies (pluriparous women, category $1+$; absence of previous pregnancies, 0 . The latter is taken as reference category).

We were interested in assessing whether socio-economic disadvantages (sed) are linked with PNC use in Umbria. We therefore calculated a deprivation index for the $92 \mathrm{mu}-$ nicipalities of the region on the basis of census data for the year 2001, provided by the Italian Institute of Statistics. Five variables $^{\mathrm{g}}[11]$, suitably standardized ${ }^{\mathrm{h}}$ [15], were used to construct the index. The final index was obtained as the sum of the standardized scores and then categorized on the basis of the quartiles of the observed score distribution $\left(\operatorname{sed}_{1}, \operatorname{sed}_{2}, \operatorname{sed}_{3}, \operatorname{sed}_{4}\right)$. We used the first quartile $\left(\operatorname{sed}_{1}\right)$ as the reference category; the other categories indicate increasing levels of socio-economic deprivation.

\section{Statistical methods}

In order to analyze the relationship between PNC (Y) use and individual and contextual characteristics $(\mathrm{X})$, we first used a basic logistic regression model. This model was then augmented by including municipal-level fixed effects (i.e., FE-Logit), which accounted for the influence of territorial differences. For the sake of simplicity, we omitted time effects and wrote the model as follows:

$$
\ln \left[\frac{P\left(Y_{i} \mid X_{i}\right)}{1-P\left(Y_{i} \mid X_{i}\right)}\right]=\beta_{0}+\sum_{k=1}^{K_{1}} \beta_{k} X_{k i}+\sum_{k=K_{1}+1}^{K_{2}} \beta_{k} M_{k}+\varepsilon_{i}
$$

where covariate vector $X_{k i}$ contains the variables at the individual level already described in the previous subsection, and five time dummies. With this specification, the set of dummy variables $M_{k}$ mimics the influence of the unobservable characteristics of the mother's place of residence and $\varepsilon_{i}$ is the residual term.

Since we were also interested in characterizing socioeconomic inequalities on PNC services - which may depend on where a woman lives - we proposed a multilevel logistic model. Equation 2 defines a logistic regression with two levels of aggregation, individual $i$ and municipality $j$, written in log-odds form as:

$$
\ln \left[\frac{P\left(Y_{i j} \mid X_{i j}\right)}{1-P\left(Y_{i j} \mid X_{i j}\right)}\right]=\beta_{0}+\sum_{k=1}^{K} \beta_{k i j} X_{k i j}+u_{j}
$$

with

$$
u_{j} \approx N\left(0, \sigma_{u}\right)
$$

where $u_{j}$ is the error term at the municipal level and $\sigma_{u}$ is the between-group variance or residual variance across municipal areas, which allowed us to estimate the model under random effects (RE-Logit) ${ }^{\mathrm{i}}$ [20].
This framework had the advantage of potentially identifying determinants of PNC inequalities through the inclusion of municipal-level variables, which in our analysis are represented by the deprivation index. The aim of this strategy was to test whether, after including municipal-level indicators, we could reduce the unexplained variance of $Y$ across geographical areas of Umbria $\left(\mathrm{RE}_{\mathrm{M}}\right.$-Logit specification). In addition, each model includes time dummies. According to variations in the odds ratio (OR), we ascertained whether PNC use changed over time and examined the degree of success of recent regional efforts to ensure that pregnant women were directly informed by their doctors or indirectly by publicity campaigns about the health advantages of following PNC recommendations.

\section{Results}

The study population from which our sample was drawn collected information on around 550,000 births from 549 hospitals in Italy. The percentage of women making the first visit later than the 12th gestational week in the population is $2.9 \%$, and increases to about $15 \%$ for foreignborn, poorly educated and young women [21]. In this paper we use a subsample obtained from the Umbria region that collects information on approximately 8,000 deliveries each year.

Descriptive statistics for the two PNC outcomes of interest from our sample, conditional on covariates, are listed in Table 1. We observe that women making a lower number of visits tend to be younger and less educated with respect to women making a recommended number of prenatal visits. The same result holds true for women born outside of Europe, $16.94 \%$ of whom had fewer than 4 visits, compared with $5.29 \%$ for women of Italian nationality. Higher percentages of employed mothers follow recommendations and have four or more antenatal examinations. Differences in the use of PNC between married and unmarried women seems to be irrelevant, whereas pluriparous women seem to make fewer antenatal visits with respect to their reference category. Similar patterns are observed in relation to the timing of the first examination, suggesting a large positive correlation between these indicators. Living in more deprived areas does not seem to have any particular influence on PNC services. Results from the descriptive analysis will be formally tested with multivariate logistic regression models.

Table 1 also shows that there is an increasing trend in PNC use for both indicators. Overall, we see that $93.48 \%$ of pregnant women make more than four prenatal visits and that $92 \%$ make their first visit before the 12th gestational week. However, for the most disadvantaged groups of the population (i.e., poorly educated, unemployed, foreign-born and unmarried) such percentages decrease to a range from $80 \%$ to $90 \%$ (see Table 1, columns 6 and 11). 
Table 1 Descriptive statistics

\begin{tabular}{|c|c|c|c|c|c|c|c|c|c|c|c|}
\hline \multirow{3}{*}{ Variable } & \multirow{3}{*}{ Category } & \multicolumn{5}{|c|}{ Number of visits } & \multicolumn{5}{|c|}{ First visit } \\
\hline & & \multicolumn{2}{|c|}{$<4$} & \multicolumn{2}{|c|}{$\geq 4$} & \multirow{2}{*}{$\begin{array}{c}\text { Total } \\
\mathbf{n}\end{array}$} & \multicolumn{2}{|c|}{$\geq 12$ weeks } & \multicolumn{2}{|c|}{$<12$ weeks } & \multirow{2}{*}{$\begin{array}{c}\text { Total } \\
\mathrm{n}\end{array}$} \\
\hline & & $\mathrm{n}$ & $\%$ & $\mathrm{n}$ & $\%$ & & $\mathrm{n}$ & $\%$ & $\mathrm{n}$ & $\%$ & \\
\hline \multirow[t]{4}{*}{ Maternal age } & $\leq 20$ & 206 & 19.64 & 843 & 80.36 & 1049 & 149 & 14.23 & 898 & 85.77 & 1047 \\
\hline & $20-29$ & 1418 & 10.73 & 11802 & 89.27 & 13220 & 1147 & 8.71 & 12022 & 91.29 & 13169 \\
\hline & $30-39$ & 1415 & 5.93 & 22438 & 94.07 & 23853 & 1239 & 5.21 & 22564 & 94.79 & 23803 \\
\hline & $>39$ & 201 & 7.36 & 2529 & 92.64 & 2730 & 154 & 5.65 & 2570 & 94.35 & 2724 \\
\hline \multirow[t]{3}{*}{ Maternal nationality } & ITA & 1630 & 5.29 & 29182 & 94.71 & 30812 & 1341 & 4.36 & 29402 & 95.64 & 30743 \\
\hline & EU-27 & 473 & 16.94 & 2319 & 83.06 & 2792 & 371 & 13.36 & 2406 & 86.64 & 2777 \\
\hline & Extra EU-27 & 1170 & 17.36 & 5571 & 82.64 & 6741 & 1069 & 15.93 & 5643 & 84.07 & 6712 \\
\hline \multirow[t]{3}{*}{ Maternal education } & High & 515 & 4.71 & 10427 & 95.29 & 10942 & 491 & 4.5 & 10431 & 95.5 & 10922 \\
\hline & Medium & 1528 & 6.91 & 20590 & 93.09 & 22118 & 1175 & 5.32 & 20891 & 94.68 & 22066 \\
\hline & Low & 1376 & 13.15 & 9091 & 86.85 & 10467 & 1159 & 11.1 & 9279 & 88.9 & 10438 \\
\hline \multirow[t]{5}{*}{ Maternal employment } & White-collar & 288 & 5.12 & 5341 & 94.88 & 5629 & 247 & 4.4 & 5373 & 95.6 & 5620 \\
\hline & Blue-collar & 1128 & 5.04 & 21238 & 94.96 & 22366 & 925 & 4.14 & 21396 & 95.86 & 22321 \\
\hline & Unemployed & 523 & 12.4 & 3695 & 87.6 & 4218 & 423 & 10.06 & 3780 & 89.94 & 4203 \\
\hline & Student & 75 & 11.19 & 595 & 88.81 & 670 & 58 & 8.68 & 610 & 91.32 & 668 \\
\hline & Housewife & 1402 & 13.24 & 9190 & 86.76 & 10592 & 1165 & 11.03 & 9397 & 88.97 & 10562 \\
\hline \multirow[t]{2}{*}{ Marital status } & Married & 2528 & 7.44 & 31441 & 92.56 & 33969 & 2189 & 6.46 & 31707 & 93.54 & 33896 \\
\hline & Unmarried & 900 & 9.28 & 8802 & 90.72 & 9702 & 639 & 6.61 & 9026 & 93.39 & 9665 \\
\hline \multirow[t]{2}{*}{ Parity } & 0 & 1746 & 6.67 & 24430 & 93.33 & 26176 & 1386 & 5.31 & 24712 & 94.69 & 26098 \\
\hline & $1+$ & 1693 & 9.61 & 15927 & 90.39 & 17620 & 1464 & 8.33 & 16114 & 91.67 & 17578 \\
\hline \multirow[t]{4}{*}{ Deprivation index } & sed 1 & 959 & 8.66 & 10115 & 91.34 & 11074 & 738 & 6.68 & 10317 & 93.32 & 11055 \\
\hline & $\operatorname{sed} 2$ & 870 & 7.3 & 11046 & 92.7 & 11916 & 969 & 8.16 & 10910 & 91.84 & 11879 \\
\hline & sed3 & 970 & 7.6 & 11799 & 92.4 & 12769 & 613 & 4.82 & 12115 & 95.18 & 12728 \\
\hline & $\operatorname{sed} 4$ & 642 & 7.98 & 7407 & 92.02 & 8049 & 530 & 6.6 & 7495 & 93.4 & 8025 \\
\hline \multirow[t]{6}{*}{ Year } & 2005 & 659 & 9.22 & 6492 & 90.78 & 7151 & 604 & 8.48 & 6520 & 91.52 & 7124 \\
\hline & 2006 & 571 & 7.92 & 6638 & 92.08 & 7209 & 564 & 7.84 & 6626 & 92.16 & 7190 \\
\hline & 2007 & 560 & 7.9 & 6531 & 92.1 & 7091 & 474 & 6.7 & 6598 & 93.3 & 7072 \\
\hline & 2008 & 601 & 7.85 & 7054 & 92.15 & 7655 & 411 & 5.39 & 7216 & 94.61 & 7627 \\
\hline & 2009 & 531 & 7.2 & 6842 & 92.8 & 7373 & 432 & 5.87 & 6929 & 94.13 & 7361 \\
\hline & 2010 & 519 & 7.08 & 6810 & 92.92 & 7329 & 365 & 4.99 & 6948 & 95.01 & 7313 \\
\hline Total & & 2850 & 6.52 & 40837 & 93.48 & 43687 & 3441 & 7.85 & 40367 & 92.15 & 43808 \\
\hline
\end{tabular}

Note: The socio-economic deprivation index is built as already described in the Methods section.

Table 2 lists the estimated odds ratio when the dependent variable is the number of prenatal examinations. The estimates under the FE-Logit model are shown in the second column; column 3 lists those obtained under the random effects specification (RE-Logit), extended in column 4 to include the deprivation index at the municipal level $\left(\mathrm{RE}_{\mathrm{M}}\right.$-Logit). Since we are particularly interested in testing whether deprivation is correlated with the number of prenatal visits, conditional on individual characteristics, we discuss here only the estimates of the multi-level model, based on evidence that the difference between the magnitudes of the coefficients of socio-demographic variables is statistically negligible across the other specifications (see Table 2).

Second-level variance component $\sigma_{\mathrm{u}}$ is 0.68 (s.e. $=0.076$ ), and intra-class correlation coefficient $\rho$ is 0.12 (s.e. = $0.024)$. This means that $12 \%$ of the variability in differences in healthcare use is not explained by the individual variables. More importantly, the coefficients associated with the municipal-level deprivation index are not significant, and the estimates of the other individual-level maternal characteristics do not change when it is included.

Many of the individual socio-demographic variables clearly have significant links with LPV. From the results 
Table 2 Estimates of socio-demographics for access to prenatal care

\begin{tabular}{|c|c|c|c|c|c|c|}
\hline \multirow{2}{*}{$\begin{array}{l}\text { Variables } \\
\text { Age } \leq 20\end{array}$} & \multirow{2}{*}{$\frac{\text { Logit }}{1.40^{* * *}}$} & \multirow{2}{*}{$\frac{\text { FE-logit }}{1.38^{* * *}}$} & \multirow{2}{*}{$\frac{\text { RE-Logit }}{1.38^{* * *}}$} & \multirow{2}{*}{$\frac{\mathbf{R E}_{\mathbf{M}} \text {-Logit }}{1.38^{* * *}}$} & \multicolumn{2}{|c|}{$\mathrm{Cl}(95 \%)$} \\
\hline & & & & & 1.13 & 1.7 \\
\hline & $(0.141)$ & $(0.144)$ & $(0.143)$ & $(0.143)$ & & \\
\hline \multirow[t]{2}{*}{ Age $30-39$} & $0.86^{* * *}$ & $0.84^{* * *}$ & $0.84^{* * *}$ & $0.84^{* * *}$ & 0.76 & 0.93 \\
\hline & $(0.042)$ & $(0.043)$ & $(0.042)$ & $(0.042)$ & & \\
\hline \multirow[t]{2}{*}{ Age $>39$} & 0.88 & $0.84^{*}$ & $0.84^{*}$ & $0.84^{*}$ & 0.7 & 1.03 \\
\hline & $(0.087)$ & $(0.084)$ & $(0.083)$ & $(0.083)$ & & \\
\hline \multirow[t]{2}{*}{ Nationality: EU-27 } & $2.72^{* * *}$ & $2.58^{* * *}$ & $2.59^{* * *}$ & $2.59^{* * *}$ & 2.25 & 2.98 \\
\hline & $(0.183)$ & $(0.186)$ & $(0.186)$ & $(0.186)$ & & \\
\hline \multirow[t]{2}{*}{ Nationality: Extra EU-27 } & $2.94^{* * *}$ & $2.94^{* * *}$ & $2.92^{* * *}$ & $2.92^{* * *}$ & 2.63 & 3.26 \\
\hline & $(0.150)$ & $(0.162)$ & $(0.161)$ & $(0.161)$ & & \\
\hline \multirow[t]{2}{*}{ Education: Medium } & 0.94 & 0.99 & 0.99 & 0.99 & 0.88 & 1.12 \\
\hline & $(0.057)$ & $(0.061)$ & $(0.061)$ & $(0.061)$ & & \\
\hline \multirow[t]{2}{*}{ Education: Low } & $1.26^{* * *}$ & $1.37^{* * *}$ & $1.36^{* * *}$ & $1.36^{* * *}$ & 1.2 & 1.55 \\
\hline & $(0.082)$ & $(0.091)$ & $(0.091)$ & $(0.091)$ & & \\
\hline \multirow[t]{2}{*}{ Occupation: Blue collar } & $0.86^{*}$ & $0.87^{*}$ & $0.87^{*}$ & $0.88^{*}$ & 0.75 & 1.02 \\
\hline & $(0.067)$ & $(0.069)$ & $(0.069)$ & $(0.069)$ & & \\
\hline \multirow[t]{2}{*}{ Occupation: Unemployed } & $1.25^{* *}$ & $1.60^{* * *}$ & $1.56^{* * *}$ & $1.56^{* * *}$ & 1.29 & 1.88 \\
\hline & $(0.115)$ & $(0.154)$ & $(0.149)$ & $(0.149)$ & & \\
\hline \multirow[t]{2}{*}{ Occupation: Student } & $1.51^{* *}$ & $1.34^{*}$ & $1.35^{*}$ & $1.35^{*}$ & 0.97 & 1.87 \\
\hline & $(0.254)$ & $(0.225)$ & $(0.225)$ & $(0.225)$ & & \\
\hline \multirow[t]{2}{*}{ Occupation: Housewife } & $1.36^{* * *}$ & $1.33^{* * *}$ & $1.34^{* * *}$ & $1.34^{* * *}$ & 1.14 & 1.58 \\
\hline & $(0.110)$ & $(0.112)$ & $(0.112)$ & $(0.113)$ & & \\
\hline \multirow[t]{2}{*}{ Marital status: Unmarried } & $1.17^{* * *}$ & $1.15^{* *}$ & $1.15^{* * *}$ & $1.15^{* * *}$ & 1.04 & 1.28 \\
\hline & $(0.060)$ & $(0.061)$ & $(0.061)$ & $(0.061)$ & & \\
\hline \multirow[t]{2}{*}{ Parity: $1+$} & $1.57^{* * *}$ & $1.59^{* * *}$ & $1.58^{* * *}$ & $1.58^{* * *}$ & 1.44 & 1.73 \\
\hline & $(0.071)$ & $(0.073)$ & $(0.072)$ & $(0.072)$ & & \\
\hline \multirow[t]{2}{*}{ Deprivation index: $\operatorname{sed}_{2}$} & & & & 1.35 & 0.6 & 3.06 \\
\hline & & & & $(0.564)$ & & \\
\hline \multirow[t]{2}{*}{ Deprivation index: $\mathrm{sed}_{3}$} & & & & 1.29 & 0.88 & 1.9 \\
\hline & & & & $(0.255)$ & & \\
\hline \multirow[t]{2}{*}{ Deprivation index: $\operatorname{sed}_{4}$} & & & & 1.14 & 0.7 & 1.84 \\
\hline & & & & $(0.279)$ & & \\
\hline \multirow[t]{2}{*}{ Year: 2006} & 1 & 0.97 & 0.98 & 0.98 & 0.85 & 1.11 \\
\hline & $(0.066)$ & $(0.065)$ & $(0.066)$ & $(0.066)$ & & \\
\hline \multirow[t]{2}{*}{ Year: 2007} & $0.83^{* * *}$ & $0.78^{* * *}$ & $0.78^{* * *}$ & $0.78^{* * *}$ & 0.68 & 0.9 \\
\hline & $(0.058)$ & $(0.055)$ & $(0.056)$ & $(0.056)$ & & \\
\hline \multirow[t]{2}{*}{ Year: 2008} & $0.62^{* * *}$ & $0.60^{* * *}$ & $0.60^{* * *}$ & $0.60^{* * *}$ & 0.52 & 0.7 \\
\hline & $(0.045)$ & $(0.044)$ & $(0.044)$ & $(0.044)$ & & \\
\hline Year: 2009 & $0.74^{* * *}$ & $0.71^{* * *}$ & $0.72^{* * *}$ & $0.72^{* * *}$ & 0.63 & 0.83 \\
\hline & $(0.052)$ & $(0.051)$ & $(0.051)$ & $(0.051)$ & & \\
\hline Year: 2010 & $0.58^{* * *}$ & $0.55^{* * *}$ & $0.55^{* * *}$ & $0.55^{* * *}$ & 0.48 & 0.64 \\
\hline & $(0.043)$ & $(0.041)$ & $(0.042)$ & $(0.042)$ & & \\
\hline
\end{tabular}


Table 2 Estimates of socio-demographics for access to prenatal care (Continued)

\begin{tabular}{|c|c|c|c|c|c|c|}
\hline \multirow[t]{2}{*}{ Constant } & $0.05^{* * *}$ & $0.01^{* * *}$ & $0.04^{* * *}$ & $0.03^{* * *}$ & 0.03 & 0.05 \\
\hline & $(0.005)$ & $(0.010)$ & $(0.005)$ & $(0.006)$ & & \\
\hline \multirow[t]{2}{*}{$\sigma_{\mathrm{u}}$} & & & 0.68 & 0.68 & 0.54 & 0.84 \\
\hline & & & $(0.077)$ & $(0.076)$ & & \\
\hline \multirow[t]{2}{*}{$P$} & & & 0.12 & 0.12 & 0.08 & 0.18 \\
\hline & & & $(0.024)$ & $(0.024)$ & & \\
\hline LR test for $\rho=0$ & & & $478.88^{* * *}$ & $393.75^{* * *}$ & & \\
\hline Observations & 36,993 & 36,717 & 36,993 & 36,993 & & \\
\hline Adj. R-squared & 0.08 & 0.12 & & . & & \\
\hline Number of municipalities & & & 91 & 91 & & \\
\hline
\end{tabular}

Notes: The confidence interval $(\mathrm{Cl})$ at $95 \%$ significance level refers to the $\mathrm{Re}_{\mathrm{M}}$-Logit model (see text). Standard errors in brackets. Significant levels as follows: p-value ${ }^{* * *} \leq 0.01,{ }^{* *} \leq 0.05,{ }^{*} \leq 0.1$.

Outcome of interest: odds ratios between fewer than four prenatal visits (LPV) versus four or more prenatal visits (NPV).

shown in Table 2, women in the younger classes are more likely to be in the LPV category. The age class $\leq 20$ has higher odds (38\%) of being in the LPV category than the reference age class (20-29). A significant relationship between the mother's education and the number of prenatal visits can also be observed. Women with fewer than 8 years of education have estimated LPV odds that are $36 \%$ higher than those of highly educated women.

Another important risk factor for LPV is found to be associated with the mother's occupation. Women classified as unemployed or looking for their first job $[\mathrm{OR}=1.56$, (95\% CI $=1.29-1.88)]$, students $[\mathrm{OR}=1.35$, (95\% CI $=0.97$ $1.87)]$ or housewives $[\mathrm{OR}=1.34,(95 \% \mathrm{CI}=1.14-1.58)]$ have higher odds of making LPV with respect to the reference category (self-employed or white-collar workers). In contrast, women within the blue-collar category tend to follow the guidelines of making at least four visits annually $[\mathrm{OR}=0.88,(95 \% \mathrm{CI}=0.75-1.02)]^{j}[22]$, like those in the reference category.

Women born outside Italy, from both EU-27 and outside it, have odds of LPV three times higher than those of Italian women $[\mathrm{OR}=2.59$ and 2.92, for women from EU-27 and from the rest of the World, respectively]. The odds ratio for unmarried women is significant and slightly higher than one $[\mathrm{OR}=1.15,(95 \% \mathrm{CI}=1.04-1.28)]$. In addition, pluriparous women have higher odds of being in the LPV category [parity, $\mathrm{OR}=1.58,(95 \% \mathrm{CI}=1.44-1.73)$ ].

Lastly, the estimated odds ratio from time dummies indicates a substantial increase across years in the use of PNC services. With respect to 2005, LPV odds in 2009 and 2010 are $28 \%$ [OR $=0.72,(95 \% \mathrm{CI}=0.63-0.83)]$ and $45 \%$ [OR $=0.55$, (95\% CI $=0.48-0.64)]$ lower, respectively.

Table 3 lists the estimates of the relationship between socio-demographic variables and the use of PNC when LFV is used as the outcome of interest. First, as in the previous case, younger $[\mathrm{OR}=1.65,(95 \% \mathrm{CI}=1.39-1.97)]$ and unmarried women $[\mathrm{OR}=1.44,(95 \% \mathrm{CI}=1.32-1.58)]$ have higher odds of making their first visit later in pregnancy than recommended. Second, women with educational level between 9 and 13 years (i.e., medium), with respect to highly educated ones $[\mathrm{OR}=1.15$, $(95 \%$ $\mathrm{CI}=1.03-1.29)]$ have higher odds of making a late first visit. Third, although the intra-class coefficient $\rho$ is significantly different from zero, according to the likelihood ratio test, $\sigma_{\mathrm{u}}$ falls to 0.26 (s.e. $=0.042$ ) and intra-class correlation coefficient $\rho$ falls to 0.02 (s.e. $=0.006$ ) with respect to the same parameters listed in Table 2. This means that for the LFV category, a larger percentage of variability is explained by individual variables and time dummies. Fourth, the estimated coefficients associated with time dummies indicate that the odds of late access decreased by about 30\% between 2005 and 2010. All the other estimated odds ratios are very similar to those already described for the previous indicator and, for the sake of simplicity, will not be commented on here.

\section{Discussion}

This study provides evidence that the use of PNC services depends on individual socio-demographic and contextual characteristics. Our results highlight how, although prenatal healthcare services in Umbria are cost-free and available to all women, access may be prevented for some particularly vulnerable groups of the population. Given that inadequate use of PNC has a negative effect on birth outcomes (e.g., birth-weight or preterm deliveries) in Umbria, as shown by [22], it becomes relevant to understand what characteristics determine inadequate access.

In this study, in accordance with [1], we defined inadequate access as either making a low number of visits (i.e., fewer than four prenatal visits) or a late first visit (i.e., first visit after the 12th gestational week) and used multilevel logistic regressions to test whether variables with different levels of aggregation (individual and municipal) were significant in explaining differences in PNC use.

When we tested whether municipal-level deprivation affected the probability of PNC use, we found no significant 
Table 3 Estimates of socio-demographics for access to prenatal care

\begin{tabular}{|c|c|c|c|c|c|c|}
\hline \multirow{2}{*}{$\begin{array}{l}\text { Variables } \\
\text { Age } \leq 20\end{array}$} & \multirow{2}{*}{$\frac{\text { Logit }}{1.65^{* * *}}$} & \multirow{2}{*}{$\frac{\text { FE-Logit }}{1.64^{* * *}}$} & \multirow{2}{*}{$\frac{\text { RE-Logit }}{1.65^{* * *}}$} & \multirow{2}{*}{$\frac{\mathrm{RE}_{\mathbf{M}} \text {-Logit }}{1.65^{* * *}}$} & \multicolumn{2}{|c|}{$\mathrm{Cl}(95 \%)$} \\
\hline & & & & & 1.39 & 1.97 \\
\hline & $(0.149)$ & $(0.149)$ & $(0.149)$ & $(0.149)$ & & \\
\hline \multirow[t]{2}{*}{ Age $30-39$} & $0.79^{* * *}$ & $0.78^{* * *}$ & $0.79^{* * *}$ & $0.79^{* * *}$ & 0.72 & 0.86 \\
\hline & $(0.036)$ & $(0.036)$ & $(0.036)$ & $(0.036)$ & & \\
\hline \multirow[t]{2}{*}{ Age $>39$} & 0.96 & 0.97 & 0.97 & 0.97 & 0.82 & 1.15 \\
\hline & $(0.084)$ & $(0.084)$ & $(0.084)$ & $(0.084)$ & & \\
\hline \multirow[t]{2}{*}{ Nationality: EU-27 } & $2.67^{* * *}$ & $2.70^{* * *}$ & $2.69^{* * *}$ & $2.69^{* * *}$ & 2.38 & 3.05 \\
\hline & $(0.169)$ & $(0.174)$ & $(0.172)$ & $(0.172)$ & & \\
\hline \multirow[t]{2}{*}{ Nationality: Extra EU-27 } & $2.49^{* * *}$ & $2.56^{* * *}$ & $2.55^{* * *}$ & $2.55^{* * *}$ & 2.31 & 2.82 \\
\hline & $(0.127)$ & $(0.131)$ & $(0.130)$ & $(0.130)$ & & \\
\hline \multirow[t]{2}{*}{ Education: Medium } & $1.17^{* * *}$ & $1.16^{* *}$ & $1.15^{* *}$ & $1.15^{* *}$ & 1.03 & 1.29 \\
\hline & $(0.067)$ & $(0.068)$ & $(0.067)$ & $(0.067)$ & & \\
\hline \multirow[t]{2}{*}{ Education: Low } & $1.49^{* * *}$ & $1.46^{* * *}$ & $1.46^{* * *}$ & $1.45^{* * *}$ & 1.28 & 1.65 \\
\hline & $(0.094)$ & $(0.094)$ & $(0.093)$ & $(0.093)$ & & \\
\hline \multirow[t]{2}{*}{ Occupation: Blue collar } & $0.88^{*}$ & $0.88^{*}$ & $0.88^{*}$ & $0.88^{*}$ & 0.76 & 1.02 \\
\hline & $(0.064)$ & $(0.064)$ & $(0.065)$ & $(0.065)$ & & \\
\hline \multirow[t]{2}{*}{ Occupation: Unemployed } & $1.33^{* * *}$ & $1.41^{* * *}$ & $1.39 * * *$ & $1.39^{* * *}$ & 1.17 & 1.65 \\
\hline & $(0.115)$ & $(0.126)$ & $(0.123)$ & $(0.123)$ & & \\
\hline \multirow[t]{2}{*}{ Occupation: Student } & $1.54^{* * *}$ & $1.55^{* * *}$ & $1.55^{* * *}$ & $1.55^{* * *}$ & 1.15 & 2.09 \\
\hline & $(0.233)$ & $(0.235)$ & $(0.235)$ & $(0.235)$ & & \\
\hline \multirow[t]{2}{*}{ Occupation: Housewife } & $1.45^{* * *}$ & $1.39^{* * *}$ & $1.42^{* * *}$ & $1.42^{* * *}$ & 1.22 & 1.65 \\
\hline & $(0.112)$ & $(0.110)$ & $(0.111)$ & $(0.111)$ & & \\
\hline \multirow[t]{2}{*}{ Marital status: Unmarried } & $1.41^{* * *}$ & $1.45^{* * *}$ & $1.44^{* * *}$ & $1.44^{* * *}$ & 1.32 & 1.58 \\
\hline & $(0.066)$ & $(0.068)$ & $(0.068)$ & $(0.068)$ & & \\
\hline \multirow[t]{2}{*}{ Parity: 1+ } & $1.53^{* * *}$ & $1.52^{* * *}$ & $1.53^{* * *}$ & $1.53^{* * *}$ & 1.41 & 1.66 \\
\hline & $(0.064)$ & $(0.064)$ & $(0.064)$ & $(0.064)$ & & \\
\hline \multirow[t]{2}{*}{ Deprivation index: sed 2} & & & & 0.89 & 0.64 & 1.25 \\
\hline & & & & $(0.154)$ & & \\
\hline \multirow[t]{2}{*}{ Deprivation index: sed3 } & & & & 0.92 & 0.76 & 1.12 \\
\hline & & & & $(0.091)$ & & \\
\hline \multirow[t]{2}{*}{ Deprivation index: sed4 } & & & & 1.05 & 0.83 & 1.34 \\
\hline & & & & $(0.130)$ & & \\
\hline \multirow[t]{2}{*}{ Year: 2006} & $0.87^{* *}$ & $0.89^{*}$ & $0.88^{* *}$ & $0.88^{* *}$ & 0.78 & 1 \\
\hline & $(0.057)$ & $(0.058)$ & $(0.057)$ & $(0.057)$ & & \\
\hline \multirow[t]{2}{*}{ Year: 2007} & $0.86^{* *}$ & $0.86^{* *}$ & $0.86^{* *}$ & $0.86^{* *}$ & 0.75 & 0.98 \\
\hline & $(0.057)$ & $(0.057)$ & $(0.057)$ & $(0.057)$ & & \\
\hline \multirow[t]{2}{*}{ Year: 2008} & $0.84^{* * *}$ & $0.83^{* * *}$ & $0.83^{* * *}$ & $0.83^{* * *}$ & 0.73 & 0.94 \\
\hline & $(0.054)$ & $(0.054)$ & $(0.054)$ & $(0.054)$ & & \\
\hline Year: 2009 & $0.73^{* * *}$ & $0.73^{* * *}$ & $0.73^{* * *}$ & $0.73^{* * *}$ & 0.64 & 0.83 \\
\hline & $(0.049)$ & $(0.049)$ & $(0.049)$ & $(0.049)$ & & \\
\hline Year: 2010 & $0.70^{* * *}$ & $0.69^{* * *}$ & $0.69^{* * *}$ & $0.69^{* * *}$ & 0.6 & 0.78 \\
\hline & $(0.047)$ & $(0.046)$ & $(0.046)$ & $(0.046)$ & & \\
\hline
\end{tabular}


Table 3 Estimates of socio-demographics for access to prenatal care (Continued)

\begin{tabular}{|c|c|c|c|c|c|c|}
\hline \multirow[t]{2}{*}{ Constant } & $0.05^{* * *}$ & $0.03^{* * *}$ & $0.05^{* * *}$ & $0.05^{* * *}$ & 0.04 & 0.06 \\
\hline & $(0.005)$ & $(0.014)$ & $(0.005)$ & $(0.006)$ & & \\
\hline \multirow[t]{2}{*}{$\sigma_{\mathrm{u}}$} & & & 0.271 & 0.26 & 0.19 & 0.36 \\
\hline & & & $(0.042)$ & $(0.042)$ & & \\
\hline \multirow[t]{2}{*}{$P$} & & & 0.021 & 0.02 & 0.01 & 0.04 \\
\hline & & & $(0.007)$ & $(0.006)$ & & \\
\hline LR test for $\rho=0$ & & & $83.26^{* * *}$ & $66.02^{* * *}$ & & \\
\hline Observations & 37,088 & 37,024 & 37,088 & 37,088 & & \\
\hline Adj. R-squared & 0.08 & 0.09 & . & & & \\
\hline Number of municipalities & & & 91 & 91 & & \\
\hline
\end{tabular}

Notes: The confidence interval $(\mathrm{Cl})$ at $95 \%$ significance level refers to the $\mathrm{Re}_{\mathrm{M}}$-Logit model (see text). Standard errors in brackets. Significant levels as follows: p-value ${ }^{* * *} \leq 0.01,{ }^{* *} \leq 0.05,{ }^{*} \leq 0.1$.

Outcome of interest: odds ratios between being late in first visit (LFV) versus regular timing of first visit (RFV).

effects. Our results are in accordance with those presented in the review of the literature proposed recently by $[16,23]$. However, we cannot exclude that an influence exists, at least at the individual level. In fact, [24] found that the perception of care differs according to the level of 'engagement" [17] and showed how lower levels of this perception are evident in most of the 'least deprived' groups and in almost none of the 'most deprived' groups. However, in his study this measure also becomes statistically less important when aggregate indicators are used.

We also analyzed the effect of individual-level variables on PNC use. Our results show how young, poorly educated, unmarried, pluriparous and unemployed women have higher probabilities of making inadequate use of PNC services. These results were also confirmed by previous studies $[7,17,25]$, which showed that young age and pluriparous women were at significantly higher risk of inadequate PNC use. Moreover, [26] showed that young age was also associated with higher rates of low birth weight and preterm deliveries. Poorly educated women had a higher propensity to make LPV and LFV; however, the magnitude of our estimated odds ratio is slightly larger than that obtained from other countries: see [27]. Our estimates also indicate a positive relation between marital status and adequate use of PNC, a result confirmed also by $[4,28]$. Disrupted family situations, such as single parenting or a poor relationship with the baby's father, significantly affect the use of PNC services [29,30]. The association of pluriparous pregnant women with low use of PNC has been reported in studies from Turkey, Indonesia and Brazil [19,20,31]. Pluriparous women may tend to rely on their previous experiences and feel more confident during the new pregnancy. In addition, our results show that mothers of non-Italian (foreign) nationality are more likely to have LPV and LFV. This result may be a consequence of poor language proficiency which, as already highlighted by [8], is a huge barrier to PNC use. Unemployment is found to be associated with higher probabilities of LPV and LFV. In fact, employed mothers may use PNC services more frequently because information about pregnancy risks is widely available in the workplace. One fact which emerges from this study is that the use of prenatal healthcare services has steadily increased over the last years in Umbria. Although we cannot attribute a causal effect, our results indicate that information campaigns about the benefits for women and newborn infants of following prenatal guidelines, promoted by the Umbria region in 2005, may have had a positive influence on PNC use.

\section{Conclusions}

This study showed how the use of PNC services is associated with individual characteristics and less influenced by contextual variables related to the level of deprivation of the mother's area of residence. We also showed that in the past years the use of PNC services has strongly increased in Umbria. This result is relevant from a policy perspective, since promotion of adequate PNC use can contribute to reducing health inequalities for newborn infants.

One limitation of our work is that, although our sample utilizes administrative data and includes all pregnant women in Umbria, it lacks information about the infants' fathers, who may be responsible for other aspects related to deprivation. Moreover, given that a relevant percentage of women are already receiving adequate care, according to the definition of inadequate use of PNC adopted in this study, it would be worthwhile also to incorporate information about content and quality of care received. Future research on this topic, using SLBC data, should include information about the infants' fathers and further enhance the definition of inadequate care by including information about quality and quantity of care received and providing estimates of the influence of inadequate access on preterm deliveries or low birth weight. 


\section{Endnotes}

${ }^{a}$ This perspective is not completely shared in the literature. For example, [32] showed that in China, since the early 1980s, utilization of maternal healthcare services has grown and antenatal and maternal health indicators have improved, whereas the meta-analysis by [33] found that reducing the number of prenatal examinations did not lead to increased adverse outcomes for the infant.

${ }^{\mathrm{b}}$ For a comprehensive review, see [34].

${ }^{\mathrm{c}}$ The recommended indicators of perinatal health also include those related to the management of sub-fertility and the care of preterm infants, describing variations in the use and success of these medical technologies in chronological order from pre-conception to postpartum care. For discussions, see [35,36].

${ }^{\mathrm{d}}$ As reported by [37,38]: "there is still no consensus about the optimal number of prenatal visits". The choice of the threshold varies among medical studies, our paper refers to the "WHO Antenatal Care Randomized Trial: Manual for the implementation of the New Model", used to justify the choice of the threshold of four recommended prenatal visits.

${ }^{\mathrm{e}}$ This indicator is also recommended by [39].

${ }^{\mathrm{f}} \mathrm{We}$ decided to analyze these indicators separately because we were interested in assessing if there were significant differences, from a statistical perspective, about the effect of socio-demographics on PNC access use, which a joint analysis would have not been able to do.

${ }^{\mathrm{g}}$ The variables included in the deprivation index are: \% of individuals who did not complete compulsory education, \% of unemployed individuals or looking for their first job, number of individuals per dwelling, \% of rented accommodation, $\%$ of single parents living with at least one child.

${ }^{\mathrm{h}}$ Each component of the index was standardized as follows: $z_{i}=\left(x_{i}-\mu_{x i}\right) / \sigma_{x i}$, where $z_{i}$, with $i=1, \ldots, 5$ is the standardized $\mathrm{i}$-th component of the deprivation index, $\mathrm{x}_{\mathrm{i}}$ is the raw $\mathrm{i}$-th index, and $\mu_{\mathrm{xi}}$ and $\sigma_{\mathrm{xi}}$ are the means and standard deviations of raw index $i$.

${ }^{\mathrm{i}}$ See [40].

${ }^{j} A$ test between blue-collars and self-employed or whitecollars coefficients did not reject the null hypothesis of equality.

${ }^{\mathrm{k}}$ Engagement is defined as personalization and active involvement in care, power and relationships, as well as healthcare literacy.

\section{Competing interests}

The authors declare that they have no competing interests.

\section{Authors' contributions}

All the authors contributed to designing the structure of the study. MC and LM contributed to conceptualizing the ideas of this study. MC defined the background of the study. LS performed the statistical analysis, described results and reviewed the manuscript. DL interpreted and discussed results and reviewed the manuscript. LM interpreted results and also obtained funding. All authors read and approved the final manuscript.

\section{Acknowledgements}

This work has been supported by a grant from the Public Health Department of the Umbria Region. We thank the participants in the 7th EUPHA meeting, 7-10 November 2012 - Malta, for their valuable comments and suggestions.

\section{Author details}

${ }^{1}$ Department of Experimental Medicine, Public Health Section, University of Perugia, Perugia, Italy. ${ }^{2}$ Department of Economics, Statistics and Finance, University of Perugia, Perugia, Italy.

Received: 12 February 2013 Accepted: 11 April 2014 Published: 15 April 2014

\section{References}

1. World Health Organization: WHO Antenatal Care Randomized Trial: Manual for the Implementation of the New Model, WHO programme to map best reproductive health practices, WHO/RHR/01.30. World Health Organization; 2002.

2. Beeckman K, Louckx F, Putman K: Determinants of the number of antenatal visits in a metropolitan region. BMC Public Health 2010, 10:527.

3. Andersen R, Newman JF: Societal and individual determinants of medical care utilization in the United States. The Milbank Memorial Fund Quarterly. Health Soc 1973, 51:95-124

4. Essex C, Counsell A, Geddis D: The demographic characteristics of early and late attenders for antenatal care. Aust N Z J Obstet Gynaecol 1992, 32(4):306-308.

5. Kupek E, Petrou S, Vause S, Maresh M: Clinical, provider and sociodemographic predictors of late initiation of antenatal care in England and Wales. BJOG 2002, 109:265-273.

6. Ayoola A, Nettleman M, Stommel M, Canady R: Time of pregnancy recognition and prenatal care use: a population-based study in the United States. Birth 2010, 37:37-43.

7. Perloff J, Jaffee K: Late entry into prenatal care: the neighborhood context. Soc Work 1999, 44:116-128.

8. Alderliesten M, Vrijkotte T, van der Wal M, Bonsel G: Late start of antenatal care among ethnic minorities in a large cohort of pregnant women. BJOG 2007, 114:1232-1239.

9. Neupane S, Doku D: Determinants of time of start of prenatal care and number of prenatal care visits during pregnancy among Nepalese women. J Community Health 2012, 37(4):865-873.

10. Johnson A, Hatcher B, El-Khorazaty M, Milligan R, Bhaskar B, Rodan M, Richards L, Wingrove B, Laryea $\mathrm{H}$ : Determinants of inadequate prenatal care utilization by African-American women. $J$ Health Care Poor Underserved 2007, 18:620-636.

11. Beeckman K, Louckx F, Putman K: Predisposing, enabling and pregnancyrelated determinants of late initiation of prenatal care. Matern Child Health J 2011, 15(7):1067-1075.

12. Trinh L, Rubin G: Late entry to antenatal care in New South Wales. Aust Reprod Health 2006, 3:8.

13. Quelopana A, Champion J, Salazar B: Factors predicting the initiation of prenatal care in Mexican women. Midwifery 2009, 25:277-285.

14. Baker E, Rajasingam D: Using trust databases to identify predictors of late booking for antenatal care within the UK. Public Health 2012, 126(2):112-116.

15. Braveman P, Bennett T, Lewis C, Egerter S, Showstack J: Access to prenatal care following major Medicaid eligibility expansions. JAMA 1993, 269:1285-1289.

16. Rowe R, Magee H, Quigley M, Heron P, Askham J, Brocklehurst P: Social and ethnic differences in attendance for antenatal care in England. Public Health 2008, 122:1363-1372.

17. Delvaux T, Buekens P, Godin I, Boutsen M: Barriers to prenatal care in Europe. Am J Prev Med 2001, 21(1):52-59.

18. Minelli L, Rampini P, Chiavarini M: Nascere in umbria. rapporto sui dati del CEDAP. Quaderni-Studi e Ricerche, Regione Umbria 14; 2009.

19. Bassani D, Surkan $P$, Olinto M: Inadequate use of prenatal services among Brazilian women: the role of maternal characteristics. Int Perspect Sex Reprod Health 2009, 35(1):15-20. 
20. Celik $K$, Hotchkiss D: The socio-economic determinants of maternal health care utilization in Turkey. Soc Sci Med 2000, 50(12):1797-1806.

21. Italian Ministry of Health: Certificato di assistenza al parto (CeDAP) Analisi dell'evento nascita. Direzione Generale del Sistema Informativo e Statistico Sanitario - Ufficio di Statistica; 2009.

22. Chiavarini M, Bartolucci F, Gili A, Pieroni L, Minelli L: Effects of individual and social factors on preterm birth and low birth weight: empirical evidence from regional data in Italy. Int J Public Health 2012, 57:261-268.

23. Hollowell J, Kurinczuk J, Oakley L, Brocklehurst P, Gray R: A systematic review of antenatal care programmes to reduce infant mortality and its major causes in socially disadvantaged and vulnerable women. National Perinatal Epidemiology Unit, University of Oxford; 2009.

24. Docherty A: Does the socioeconomic background of pregnant women make a difference to their perceptions of antenatal care? A qualitative case study, PhD thesis. University of Stirling; 2010.

25. Heaman M, Green C, New-burn Cook C, Elliot L, Helewa M: Social inequalities in use of prenatal care in Manitoba. J Obstet Gynaecol 2007, 29(10):806-816.

26. Olausson P, Cnattingius S, Haglund B: Does the increased risk of preterm delivery in teenagers persist in pregnancies after the teenage period. BJOG 2001, 108:721-725.

27. Feijen-de Jong $E$, Jansen $D$, Baarveld $F$, van der Schans $P$, Schellevis $F$, Reijneveld S: Determinants of late and/or inadequate use of prenatal healthcare in high-income countries: a systematic review. Eur J Public Health 2012, 22(6):904-913.

28. Rogers M, Peoples-Sheps M, Suchindran C: Impact of a social support program on teenage prenatal care use and pregnancy outcomes. J Adolesc Health 1996, 19(2):132-140.

29. Zambrana R, Dunkel-Schetter C, Scrimshaw S: Factors which influence use of prenatal care in low-income racial-ethnic women in Los Angeles County. J Community Health 1991, 16(5):283-295.

30. Zambrana R, Scrimshaw S, Dunkel-Schetter C: Prenatal care and medical risk in low-income, primiparous, Mexican-origin and African-American women. Fam Syst Health 1996, 14(3):349-359.

31. Titaley C, Dibley M, Roberts C: Factors associated with underutilization of antenatal care services in Indonesia: results of Indonesia Demographic and Health Survey 2002/2003 and 2007. BMC Public Health 2010, 10:485.

32. Liu $X$, Yan H, Wang D: The evaluation of safe motherhood program on maternal care utilization in rural western China: a difference in difference approach. BMC Public Health 2010, 10:566.

33. Villar J, Carroli G, Khan-Neelofur D, Piaggio G, Gulmezoglu M: Patterns of routine antenatal care for low-risk pregnancy. Cochrane Database Syst Rev 2004, 4:1-10.

34. Rowe R, Garcia J: Social class, ethnicity and attendance for antenatal care in the United Kingdom: a systematic review. J Public Health Med 2003, 25(2):113-119.

35. Macfarlane A, Gissler M, Bolumar F, Rasmussen S: Availability of perinatal health indicators in Europe. Eur J Obstet Gynecol Reprod Biol 2003, 111(1):S15-S32.

36. Zeitlin J, Wildman K, Bréart G, Alexander S, Barros H, Blondel B, Buitendijk S, Gissler M, Macfarlane A, PERISTAT Scientific Advisory Committee: Indicators for monitoring and evaluating perinatal health in Europe. Eur J Obstet Gynecol Reprod Biol 2003, 111(1):S5-S14.

37. Krueger $\mathrm{P}, \mathrm{SchollT}$ : Adequacy of prenatal care and pregnancy outcome. J Am Osteopath Assoc 2000, 100(8):485-492.

38. Raatikainen $\mathrm{K}$, Heiskanen $\mathrm{N}$, Heinonen $\mathrm{S}$ : Under-attending free antenatal care is associated with adverse pregnancy outcomes. BMC Public Health 2007, 7:268

39. EURO-PERISTAT: European Perinatal Health Report: EURO-PERISTAT; 2008

40. Pickett $\mathrm{K}$, Pearl M: Multilevel analyzes of neighborhood socioeconomic context and health outcomes: a critical review. J Epidemiol Community Health 2001, 55(2):111-122.

doi:10.1186/1472-6963-14-174

Cite this article as: Chiavarini et al:: Socio-demographic determinants and access to prenatal care in Italy. BMC Health Services Research 2014 14:174.

\section{Submit your next manuscript to BioMed Central and take full advantage of:}

- Convenient online submission

- Thorough peer review

- No space constraints or color figure charges

- Immediate publication on acceptance

- Inclusion in PubMed, CAS, Scopus and Google Scholar

- Research which is freely available for redistribution 